\title{
UNDER VOLTAGE LOAD SHEDDING FOR CONTINGENCY ANALYSIS TO OPTIMIZE POWER LOSS AND VOLTAGE STABILITY MARGIN
}

\author{
Shiwani Rai ${ }^{1}$, Yogendra Kumar ${ }^{2}$ and Ganga Agnihotri ${ }^{3}$ \\ Department of Electrical engineering Engineering, Maulana \\ Azad National Institute of Technology Bhopal, India.
}

\begin{abstract}
Power system contingency is a condition of operation which may be caused due to line outage in a system and could lead to entire system voltage instability. This may further result in voltage collapse leading to total blackout of the system. Therefore, voltage collapse prediction and estimating voltage stability margin is an important task in power system operation and planning. In this paper Line Stability Index Lij utilizing the concept of power flow in a single line is adopted to determine the condition of voltage instability. The purpose of Lij is to determine the point of voltage instability, the weakest bus in the system and the critical line referred to a bus. Analytical approach based technique for load shedding has been developed as a solution for secured operation of power system under various contingency conditions to optimize the power flow in order to minimize the system losses within acceptable limit. To validate the effectiveness of the proposed method simulation has been carried out on IEEE 14 bus system.
\end{abstract}

\section{KEYWORDS}

Voltage stability assessment, Voltage collapse, Contingency analysis, Line voltage stability index, Undervoltage load shedding.

\section{INTRODUCTION}

In deregulated environment voltage instability is a growing problem, as systems are interconnected and are always operating near stability limit and also operating point of the system changes continually, which results in rapid voltage drop leading to voltage collapse. In the last some decades there has been various voltage collapse events reported throughout the world. This had emphasized on the need for continuous voltage stability analysis, so that system can be prevented to reach emergency state of operation. To alleviate the problem of voltage collapse load shedding is a very effective technically feasible and economic tool. In a present day deregulated environment when system operating condition changing continually, to meet the existing demand satisfying stability and reliability criteria, existing lines must be utilized efficiently [1].

When the supplying company receives more demand for electrical power than its generating or transmission or installed capacity can deliver, the company has to resort to rationing of the available electricity to its customers. This act is called load shedding. Load shedding can also be referred to Demand Side Management or load management. Demand controller devices are used to shed loads when a pre-set $\mathrm{kW}$ reading has been reached. In the literature, [2-7] many methods have been reported to mitigate the problem of overloading and to obtain a secure operating point.

DOI : 10.14810/elelij.2014.3406 
A number of research papers are available on the subject of base case optimization and corrective rescheduling. Such methods [5,6] employ various performance indices for optimization and utilize linear, nonlinear or quadratic programming techniques. In [7], a local optimization based method for generation rescheduling and load shedding to alleviate line overloads is presented. In [8] Nila P Divakaran proposes a distributed multi agent based PSO and GA, which can make the efficient load shedding decision based on the global information. This method integrates the multi agent system and PSO, GA algorithm. The above mentioned methods use optimization techniques, which are complicated and time consuming from a computational point of view, especially for large systems. Under the conditions of emergency operators has to take quick decisions, compromising a little with the optimality of the operating point. Hence an efficient, reliable and direct method is always required. Corrective control actions to eliminate overloads must be determined within a small time frame, especially in case of a real time control environment. In this paper a method has been proposed to determine the proximity of voltage instability in a power system in order to provide a control strategy to be used in case of emergencies. The line voltage stability index has been used to determine the maximum line loadability to obtain secure voltage stability limit. Critical buses are ranked based on overall system losses and critical lines are identified by the maximum value of Lij under the particular bus loading and line outage condition. Main problems set up in the analysis of stationary conditions as an approach for solving the problems of voltage stability and voltage collapse are:

- Defining adequate voltage stability indicator as for indicator of voltage collapse proximity,

- Planning and locating necessary reactive power reserve in complex power systems in order to prevent voltage collapse phenomena,

- Implementing other preventive measures for improving voltage stability (such as SVC Installations, UVLS, etc.).

\section{Line Voltage StaBiLITy INDEX}

There are several indices available in literature [9-11], discussed in [12] particularly for prediction of point of voltage collapse in power system based on power flow in a single line. The performance of all these indices has been found to show high degree of accuracy and reliability. In this paper Line Stability Index Lij proposed by Moghavvemi et al [9], utilizing the concept of power flow in a single line is adopted to determine the condition of voltage instability under various contingency conditions. The purpose of $\mathrm{Lij}$ is to determine the point of voltage instability, the weakest bus in the system and the critical line referred to a bus. The Line Voltage Stability Index (Lij) referred to a line is formulated in this study as the measuring unit in predicting the voltage stability condition in the system.

Taking the symbols ' $\mathrm{i}$ ' as the sending bus and ' $\mathrm{j}$ ' as the receiving bus, Lij can be defined by:

$$
L_{i j}=\frac{4 X Q_{j}}{V_{i} \sin ^{2}(\theta-\delta)}
$$

Where,

Lij = Line Voltage Stability Index,

$\mathrm{X}=$ line reactance,

$\mathrm{Qj}=$ reactive power at the receiving end,

$\mathrm{Vi}=$ sending end voltage,

$\theta=$ angle of line reactance, 
$\delta=$ difference of angles of sending end voltage and receiving end voltage.

The conditions for Lij are:

- Any line in a system that exhibits Lij closed to unity indicates that the line is approaching its instability limit and hence may lead to system violation. Lij should always be less than unity in order to maintain a stable system.

- Collapse point is obtained when Lij reaches the value 1 or greater than 1.

\section{UNDERVOLTAGE LOAD SHEDDING}

There are many technical solutions for improving voltage stability. The most important of course is enlarging of reactive power capacity in critical zones. As discussed in [13] the potential problem of voltage instability and subsequent voltage collapse is a consequence of lack of reactive power support (locally or globally). Also the location and type of available reactive power sources too play a vital role. If the reactive power support is remote from the load centres and insufficient in size, a relatively normal contingency (such as line outage or a sudden increase in load, etc.) can invoke a significant voltage drop. It can result in motor stalling and low voltages. The reactive power requirement then increases quickly, leading to a further drop in voltage. Voltage drop results in line overloading which often results in operation of protective relays causing tripping of other lines. Due to the relatively high frequency of occurrence of these incidents in the last decade and substantial costs and consequences originating from them, a significant research effort has focused towards the study of voltage instabilities and their control. In general insuring of local and fast reactive power reserve is crucial for voltage stability enhancement. Undervoltage load shedding is one such economical and efficient method. It is relatively low cost and easy and fast to implement. Load shedding has been used to mitigate the consequences of large disturbances for many years. The execution of load shedding i.e. opening of the breaker has hardly developed over the years. The modern society dependence on reliable electricity supply and is continuously increasing. Furthermore, as a consequence of deregulation in power system traditional techniques of load shedding are not acceptable. Intelligent load shedding should be regarded as a means to improve power system stability, by providing smooth load relief in situations where the power system would go unstable. Automatic UVLS is of great significance in new deregulated environment since UVLS makes necessary measures by tripping of loads at critical buses. For the implementation of load shedding the characteristic property in general considered are location, amount and delay. Naturally the amount of load to be shed should be minimal. Location and delay should be chosen properly to insure the selectivity of UVLS.

\section{Proposed Methodology}

The proposed work has been carried out in three phases;

\subsection{Phase-I}

In this phase the system is congested by overloading all the load buses of the system one at a time. Under this condition, system violates the limits of voltage stability and collapse point is obtained. This indicates the point of voltage instability, weak bus and critical lines in the system. In this phase maximum loadability of each bus (both real and reactive power) has been obtained. The critical line (table-1) refers to a particular bus and is determined by the Lij value close to 1.00 , while the weak bus is determined by the maximum permissible load for the individual bus 
in the system. Load ranking is done by the lowest value of the maximum permissible load and the percentage increase in overall system losses, characterizes the highest rank of the bus, which is the weakest one in the system. The bus that ranked lowest is the most secure in the system.

\subsection{Phase-II}

The Branch outage contingency analysis is conducted at $50 \%$ of the maximum loading condition as obtained from phase I, considering three cases at Bus 13, 14, 5 one at a time. The computation was performed by taking line outage 1 through 20 consecutively for each different case. The values of line stability indices highlighted in the table- 2 demonstrate the highest indices after being sorted in descending order.

The basic concept here is to assign a suitable severity to each of the load bus in a system based on the indicator which accounts for the combined effect of occurrence of a specific critical line under the condition of voltage collapse and the systems proximity to voltage collapse due to bus load increase.

\subsection{Phase-III}

The results obtained from phase II shows that system approaches voltage collapse point as loads on buses grow further. This situation can appear lot of times in real power networks especially during summer or winter demand peaks. During that period of time, voltages in the system can decay and make local problems in the parts of system which afterwards can lead to total blackouts.

As a solution to the above mentioned problem suitable values for load shedding is determined for the threshold values of reactive power demand at buses 13,14,5 and the corresponding change in indices and overall system loss has been calculated. (Table-3)

\section{RESUlts AND DiscuSSION.}

\subsection{Voltage Stability Analysis (VSA)}

To validate the performance of the indicator, an IEEE 14 bus test system is used. In all the load buses $4,5,7,9,10,11,12,13,14$ both P and Q load has been increased in steps of $10 \%$ one at a time. The results are tabulated in Table 1. System for VSA is analyzed considering the maximum load, critical voltage and critical line. Form the base case, active and reactive power is increased till Lij reaches unity. Buses are ranked based on the maximum loadability and the maximum percentage increased in loss as compared to base case loading. Bus 13 is ranked 1with highest loss percentage of 7.9434; critical line is 13 connected between buses 6-13. The Lij value $(0.9999)$ at this point is close to unity indicating that the system has reached its stability limit. The critical voltage of particular bus is 0.7587 p.u.beyond this limit violation will be experienced. Similarly for all the buses results are tabulated below. 
Electrical and Electronics Engineering: An International Journal (ELELIJ) Vol 3, No 4, November 2014

Table 1. Maximum Loadability of load buses

\begin{tabular}{|l|l|l|l|l|l|l|l|l|}
\hline Rank & $\begin{array}{c}\text { Bus } \\
\text { No }\end{array}$ & $\begin{array}{c}\text { Pmax } \\
(\mathbf{M W})\end{array}$ & $\begin{array}{c}\text { Qmax } \\
(\mathbf{M V A r})\end{array}$ & $\begin{array}{c}\text { Voltage } \\
\text { p.u. }\end{array}$ & $\begin{array}{c}\text { Critical } \\
\text { Line }\end{array}$ & $\begin{array}{c}\text { Line } \\
\text { From-to }\end{array}$ & Lij & $\begin{array}{c}\text { \% increase } \\
\text { in loss }\end{array}$ \\
\hline 1 & 14 & 105 & 35.3 & 0.6868 & 20 & $13-14$ & 0.9998 & 3.8408 \\
\hline 2 & 7 & 116.7 & 116.7 & 0.8321 & 14 & $7-8$ & 0.9999 & 3.8425 \\
\hline 3 & 5 & 266.53 & 56.112 & 0.8693 & 2 & $1-5$ & 0.9999 & 4.4953 \\
\hline 4 & 11 & 124.55 & 65.5 & 0.7592 & 11 & $6-11$ & 0.9999 & 4.56846 \\
\hline 5 & 9 & 172.87 & 97.91 & 0.7704 & 9 & $4-9$ & 0.9999 & 4.7939 \\
\hline 6 & 12 & 129.45 & 34.05 & 0.7636 & 12 & $6-12$ & 0.9999 & 4.92775 \\
\hline 7 & 10 & 127.9 & 81.9 & 0.6798 & 9 & $4-9$ & 0.9998 & 5.0315 \\
\hline 8 & 4 & 353.15 & 52.85 & 0.8407 & 2 & $1-5$ & 0.9999 & 5.93978 \\
\hline 9 & 13 & 192.05 & 82.58 & 0.7587 & 13 & $6-13$ & 0.999 & 7.9434 \\
\hline
\end{tabular}

\section{2. Critical Branch Outage.}

The branch outage contingency analysis was done considering 50\% of the maximum loading as obtained from table- 1 for weak buses 13,14, and 5.bus 13 and 14 is identified as critical buses since they are capable of carrying least amount of reactive power reserve which is also logical since they has greatest electrical distance from the nearest reactive power reserves. Though bus 5 is situated near the generation facility but outage of branch 1(1-2) and 5(2-5) makes it unstable for the specific loading condition. The computation was performed by taking line outage 1 through 20 consecutively for each different case. bus 13 reaches the condition of voltage collapse much before the loading condition, the maximum load it can bear for branch outage contingency condition is $66.233 \mathrm{MW}$ and 28.533 MVAr for CBO 10 connected between buses 5and 6 and the critical line identified is 9 connected between buses $4-9$, critical voltage at this case is 0.8443 p.u. at this loading the maximum stressed value of $\mathrm{Lij}$ obtained is 0.841 , if the loading of the line increased by even $0.001 \%$ than there is a situation of cascaded line outage and even complete system may be collapsed. So the safer limit of operation for bus 13 is less than this loading. Similarly bus 14 collapses at $25 \%$ loading of base case load for CBO 17 with critical voltage 0.6724 p.u. table- 3 shows the results obtained from critical branch outage for weak buses

Table 2. Result of branch outage contingency analysis

\begin{tabular}{|l|l|l|l|l|l|l|l|l|}
\hline Rank & $\begin{array}{c}\text { Bus } \\
\text { Num. }\end{array}$ & $\begin{array}{c}\text { Pmax } \\
(\mathbf{M W})\end{array}$ & $\begin{array}{c}\text { Qmax } \\
\text { (MVAr }\end{array}$ & \multicolumn{1}{|c|}{ CBO } & $\begin{array}{c}\text { Critical } \\
\text { line }\end{array}$ & $\begin{array}{c}\text { Critical } \\
\text { Voltage } \\
(\mathbf{p u})\end{array}$ & \multicolumn{1}{|c|}{ Lij } & $\begin{array}{c}\text { \% } \\
\text { increas } \\
\text { e in loss }\end{array}$ \\
\hline 1 & 13 & 66.233 & 28.533 & $10(5-6)$ & $9(4-9)$ & 0.8443 & 0.841 & 5.3606 \\
\hline 2 & 13 & 66.233 & 28.533 & $13(6-13)$ & $19(12-13)$ & 0.5343 & 0.9891 & 3.7038 \\
\hline 3 & 13 & 96.025 & 41.29 & $1(1-2)$ & $2(1-5)$ & 0.9057 & 0.9359 & 3.6846 \\
\hline 4 & 13 & 96.025 & 41.29 & $3(2-3)$ & $6(3-4)$ & 0.9047 & 0.7598 & 4.7365 \\
\hline 5 & 14 & 50.28 & 16.87 & $17(9-14)$ & $20(13-14)$ & 0.6724 & 0.9988 & 2.1854 \\
\hline 6 & 14 & 52.5 & 17.65 & $10(5-6)$ & $20(13-14)$ & 0.8585 & 0.5582 & 3.1114 \\
\hline 7 & 5 & 98.972 & 20.832 & $1(1-2)$ & $2(1-5)$ & 0.9244 & 0.9845 & 2.8389 \\
\hline 8 & 5 & 133.266 & 28.056 & $5(2-5)$ & $2(1-5)$ & 0.901 & 0.7648 & 3.0113 \\
\hline 9 & 5 & 133.266 & 28.056 & $3(2-3)$ & $2(1-5)$ & 0.9024 & 0.7515 & 4.7535 \\
\hline 10 & 5 & 133.266 & 28.056 & $4(2-4)$ & $2(1-5)$ & 0.9049 & 0.7121 & 3.7964 \\
\hline
\end{tabular}




\subsection{Under Voltage Load Shedding.}

For the contingency condition as obtained from table-2, power system has entered to the emergency operating state, where inequality constraints are violated. To prevent the system reaching extreme condition, under voltage load shedding control strategy is adopted in this paper. The lower limit of the voltage is considered as 0.9 p.u. The UVLS is applied in steps of $5 \%$ for the critical buses 13,14 and 5. After each step of load shedding amount simulation was carried out to obtain voltage and stability index limit. The total amount of load to be shed is presented in table-3. Bus 13 Qmax 28.533 p.u. and outage of line 13 needs to shed maximum amount of load i.e. $95 \%$, even though system cannot retain its minimum voltage limit of 0.9 p.u. So the safer reactive power limit for which system can maintain its stable voltage limit is 17.00 p.u. Bus 5 needs the lowest amount of load to be shed to maintain system stability.

Table 3. Index magnitude and Voltage profile with automatic UVLS

\begin{tabular}{|l|l|l|l|l|l|l|l|}
\hline $\begin{array}{c}\text { Load } \\
\text { Shed } \\
\text { Amount } \\
(\%)\end{array}$ & $\begin{array}{c}\text { Bus } \\
\text { Num. }\end{array}$ & $\begin{array}{c}\text { Qmax } \\
\text { (MVAr) }\end{array}$ & \multicolumn{1}{|c|}{ CBO } & $\begin{array}{c}\text { Critical } \\
\text { line }\end{array}$ & $\begin{array}{c}\text { Critical } \\
\text { Voltage } \\
\text { (pu) }\end{array}$ & \multicolumn{1}{|c|}{ Lij } & $\begin{array}{c}\text { \% } \\
\text { decrease } \\
\text { in loss }\end{array}$ \\
\hline 30 & 13 & 28.533 & $10(5-6)$ & $9(4-9)$ & 0.9001 & 0.4546 & 3.2851 \\
\hline 95 & 13 & 28.533 & $13(6-13)$ & $19(12-13)$ & 0.8791 & 0.3807 & 1.0076 \\
\hline 80 & 13 & 17.00 & $13(6-13)$ & $19(12-13)$ & 0.9001 & 0.253 & 1.0146 \\
\hline 35 & 14 & 16.87 & $17(9-14)$ & $20(13-14)$ & 0.9012 & 0.3266 & 0.8922 \\
\hline 35 & 14 & 17.65 & $10(5-6)$ & $20(13-14)$ & 0.9003 & 0.46 & 2.2502 \\
\hline 25 & 5 & 20.832 & $1(1-2)$ & $2(1-5)$ & 0.9429 & 0.5669 & 2.0589 \\
\hline 20 & 5 & 28.056 & $5(2-5)$ & $2(1-5)$ & 0.916 & 0.5978 & 2.3828 \\
\hline
\end{tabular}

Figure-1 describes the voltage profile and line voltage stability indices when load is increased with critical branch outage of line 10 connected between bus 5 and 6.voltage decreases continuously with increase in load and index increases continuously which shows the voltage instability condition reaching to the state of voltage collapse. Figure- 2 describes the voltage profile and line voltage stability indices after the application of automatic UVLS, here voltage profile has been improved and the stability indices reach a secure stable value leading to system voltage stability condition.

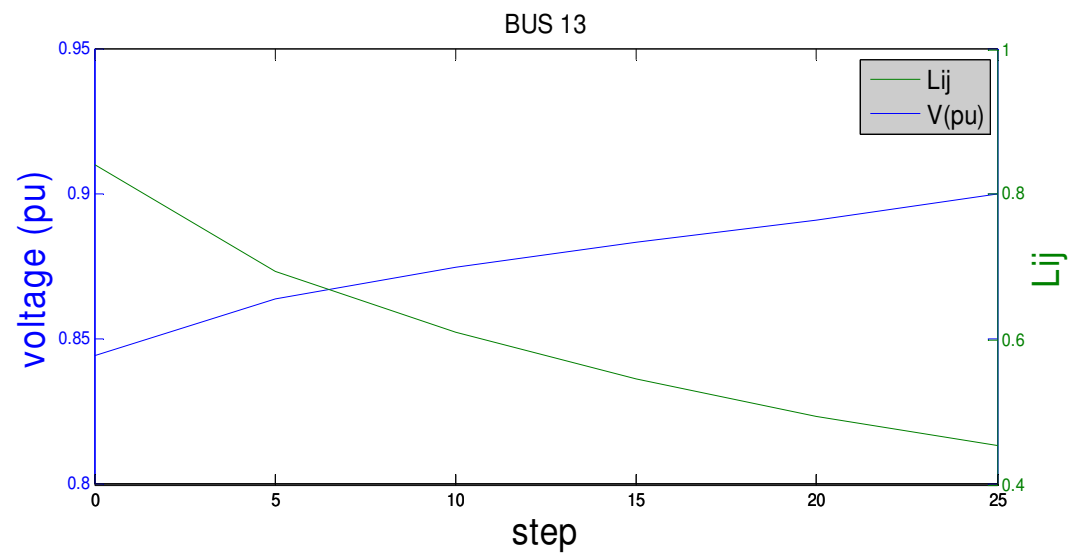

Figure 1. Functionality between voltage on critical bus 13 and Lij index versus steps of increased load without UVLS 


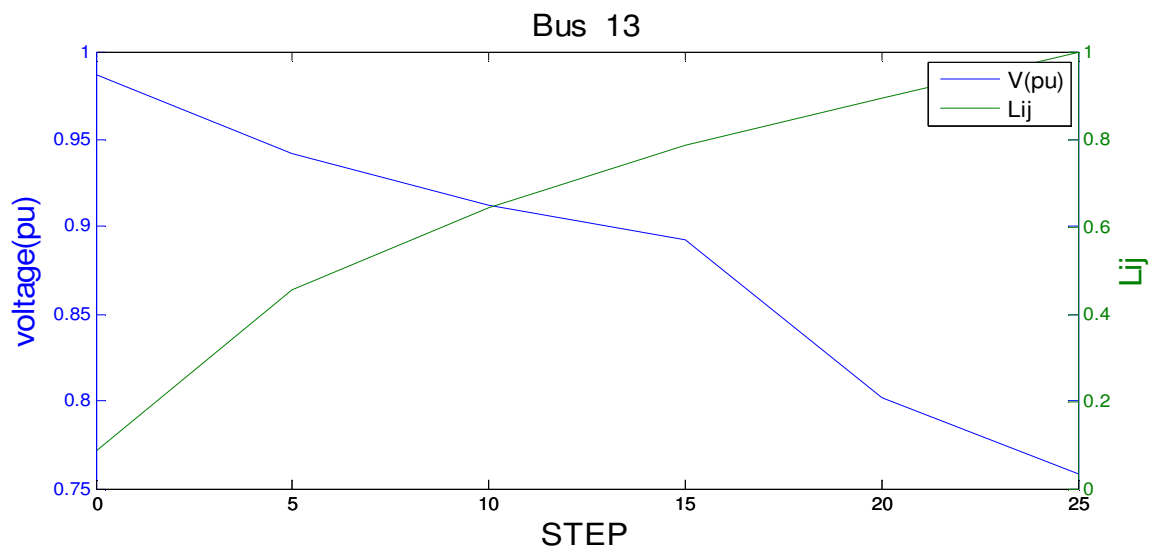

Figure 2. Functionality between voltage on critical bus 13 and Lij index versus steps of increased load with UVLS

\section{Conclusions}

In this paper one method for UVLS has been described based on voltage collapse proximity index and bus voltage magnitudes. The value of line voltage stability index used here gives relative measure of power system voltage stability and based on this value adequate measures can be taken.

In the given system for the predefined contingency conditions suitable values were taken as threshold values for UVLS based on earlier calculations of critical conditions. These values were determined heuristically. Earlier calculation without UVLS gave critical buses and threshold values for relaying. Also, it showed voltage conditions on voltage stability margins. Based on these knowledge UVLS scheme was proposed. UVLS proved to be a primary and economic solution to protect the system reaching threshold condition of voltage collapse. Generally voltage before collapsing reaches a level below $0.85 \mathrm{p}$.u. But for the system to recover completely from emergency operating state to normal operating state minimum of 0.9 p.u. of voltage should be maintained. Hence with automatic UVLS a proper load restoration scheme should be coordinated and implemented.

\section{REFERENCES}

[1] Jagabondhu Hazra and Avinash K. Sinha, "Congestion Management Using Multiobjective Particle Swarm Optimization", IEEE TRANSACTIONS ON POWER SYSTEMS, VOL. 22, NO. 4, pp. 1726-1734, NOVEMBER 2007.

[2] Medicheria, T. K. P., Billinton, R., and Schadev, M. S., "Generation Rescheduling and Load Shedding to Alleviate Line Overloads-System Studies", IEEE Trans. on Power Systems, Vol.PAS-100 (1), pp. 36-41, 1981.

[3] Mohamed, A., and Jasmon, G. B., "Realistic Power System Security Algorithm" IEEE Proc C, No.8, pp. 98-106, 1988.

[4] Kirchen, D.S., and Van Meeteren, H.P., "MW/Voltage Control in a Linear Programming Based Optimal Power Flow", IEEE Trans. on Power Apparatus and Systems, Vol. PWR-3, pp. 481-489, May 1988.

[5] Alsac, O., Bright, J., Prais, M., and Stott, B., "Further Developments in LP-Based Optimal Power Flow", IEEE Trans. on Power Systems, Vol. 5, No.3, pp. 697-711, August 1990. 
[6] Venkatesh, S. V., Liu, E., Papalexopoulos, A. D., "A Least Squares Solution for Optimal Power Flow Sensitivity Calculations", IEEE Trans. on Power Apparatus and Systems, Vol.PWRS-3, No. 1, pp. 317-324, 1988.

[7] Shandilya, A., Gupta, H., Sharma, J., "Method for Generation Rescheduling and Load Shedding to Alleviate Line Overloads Using Local Optimization”, IEEProc. C, Vo. 140, No. 5, pp. 337-342, Sept. 1993.

[8] Nila P Divakaran, A Dyaneswaran,M.E., "Stable Multi Optimized Algorithm Used For Controlling the Load Shedding Problems in Power Systems", (IOSR-JEEE) e-ISSN: 2278- 1676,p-ISSN: 23203331, Volume 5, Issue 3 (Mar. - Apr. 2013), PP 81-90

[9] Moghavvemi M, Omar FM., 'Technique for contingency monitoring and voltage collapse Prediction', IEE Proc Gen Transm Distrib 1998;145(6):634-40.

[10] Mohamed A, Jasmon GB., “A new clustering technique for power system voltage stability Prediction' Int J Electr Mach Power Syst 1995;23(4):389-403.

[11] Musirin I, Rahman TKA., "On-line voltage stability based contingency ranking using fast voltage stability index (FVSI”, In: Proc IEEE/PES transm distrib and exhibition conference;2002. p. 1118-23.

[12] Rajive Tiwari, K.R. Niazi, Vikas Gupta, "Line collapse proximity index for prediction of voltage collapse in power systems", Electrical Power and Energy Systems 41 (2012) 105- 111.

[13] M. Klaric, I. Kuzle, and S. Tesnjak, "Undervoltage Load Shedding Using Global Voltage Collapse Index” IEEE Trans. on Power Systems, April 2004.

[14] Shiwani Rai, Sudeshna Ghosh, D.Suresh Babu, P.S.Venkataramu, M.S.Nagaraja," Line Congestion Relief Using UPFC”, ICPEC, 978-1-4673-6030-pp. 58-63 2/2013 IEEE.

[15] C. Subramani, Subhransu Sekhar Dash, M. Jagdeeshkumar and M. Arun Bhaskar. "Stability Index Based Voltage Collapse Prediction and Contengency Analysis." Journal of Electrical Engineering \& Technology Vol. 4, No. 4, pp. 438-442, 2009.

\section{Authors}

Shiwani Rai received her B.E. in Electrical Engineering and M.E. degree in Power System from Rajeev Gandhi Technological University (RGTU) in 2009 and 2012 respectively. She is currently research fellow at MANIT, Bhopal, M.P. Her research interests include Power system analysis and control, FACTS devices.

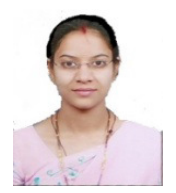

Dr Yogendra kumar received B.Sc. Eng. in Electrical (1991) from Jamia Millia Islamia New Delhi, M.Tech in heavy Electrical Eng. (1998) from MACT, Bhopal, and PhD degree (2006) from IIT Roorkee in power system. Since 1992 he is with Maulana Azad College of Technology,Bhopal. Presently he is Professor and head of the Electrical Engineering Dept. His research area includes Power system optimization and distribution automation.

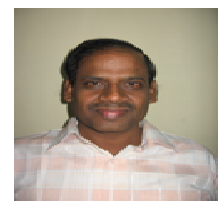

Dr. Ganga Agnihotri (M92118974) received BE degree in Electrical engineering from MACT, Bhopal (1972), the ME degree (1974) and PhD degree (1989) from University of Roorkee, India. Since 1976 she is with Maulana Azad College of Technology, Bhopal in various positions. Her research interest includes Power System Analysis, Power System Optimization and Distribution Operation.

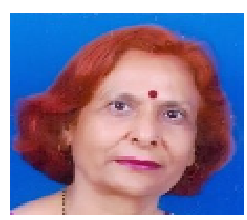

